\title{
Low Vitamin D and Cardiovascular Risk Factors in Males and Females from a Sunny, Rich Country
}

\author{
Ayman El-Menyar ${ }^{*}, 1,2$, Ali Rahil ${ }^{3}$, Khalid Dousa $^{3}$, Walid Ibrahim ${ }^{3}$, Talal Ibrahim ${ }^{3}$, Rasha Khalifa ${ }^{3}$, \\ and Mohamed Osman Abdel Rahman ${ }^{4}$
}

\author{
${ }^{1}$ Department of Clinical Medicine, Weill Cornell Medical College, Po Box 24144, Doha, Qatar \\ ${ }^{2}$ Hamad Medical corporation, Hamad General Hospital, Po Box 3050, Doha, Qatar \\ ${ }^{3}$ Department of internal medicine, Hamad General Hospital (HGH), Qatar \\ ${ }^{4}$ Department of Laboratory Medicine and Pathology, HGH, Qatar
}

\begin{abstract}
Background: Low serum vitamin (vit) D levels are common even in sunny countries. We assessed the prevalence and relationship of low vit D with cardiovascular risk factors in Qatar.

Methods: Data were collected retrospectively from January 2008 and November 2009. In patients who had low vit D (< $30 \mathrm{ng} / \mathrm{ml}$ ), demographic and clinical profiles were analyzed and compared in males and females.

Results: The overall mean level of vit D among 547 patients was $14.4 \pm 11 \mathrm{ng} / \mathrm{mL}$. Among the low vitamin D group, $56 \%$ were females (mean age $48 \pm 12$ ) and $44 \%$ males (mean age $49.6 \pm 13)$. Severely low vit D levels $(<10 \mathrm{ng} / \mathrm{mL}$ ) were found in $231(46 \%)$ patients with mean age of $46 \pm 12$ years. Compared with females, males with low vitamin D were more likely to have diabetes mellitus ( 38 vs $22 \%, \mathrm{p}=0.001$ ), dyslipidemia ( $41 \mathrm{vs} 29 \%, \mathrm{p}=0.007)$, myocardial infarction $(5.5$ vs $1.5 \%$, $\mathrm{p}=0.001)$ and angiographically documented coronary artery disease (CAD) (53 vs $17 \%, \mathrm{p}=0.001)$. Multivariate logistic regression analysis showed that in the presence of low vit $\mathrm{D}$, age and hypertension were independent predictors of $\mathrm{CAD}$ (OR 1.07;95\% CI: 1.02-1.11) and OR 8.0; 95\% CI: 1.67-39.82), respectively.

Conclusions: Our study supports the widespread prevalence of low vit D in sunny regions. Low vit D is associated with 3 times increase in the rate of MI among males. Hypertension increases the risk of CAD 8 times in the presence of low vit D regardless of gender.
\end{abstract}

Keywords: Low vitamin D, cardiovascular, risk, gender, Qatar.

\section{INTRODUCTION}

Insufficient serum vitamin (vit) D level $(<30 \mathrm{ng} / \mathrm{ml}$ or $<$ $75 \mathrm{nmol} / \mathrm{L}$ ) is a common problem worldwide [1-3]. Although sun exposure is the major source of vit $\mathrm{D}$, several reports show that low vit $\mathrm{D}$ is common in sunny regions [4-7]. Despite the sunshine, Middle Eastern populations showed a high rate of low vit $\mathrm{D}$ due to limited sun exposure based on cultural practices [8-10]. The mean 25(OH)D levels are near $25 \mathrm{nmol} / \mathrm{L}$ in Lebanese, Saudi, Emirati, and Iranian females [10-13]. In the elderly Lebanese, $37 \%$ of males and $56 \%$ of females had vit D levels $<25 \mathrm{nmol} / \mathrm{L}$ [10]. Similarly, in an international study conducted in females with osteoporosis, the highest proportion of low vit $\mathrm{D}$ was noted in the Middle East [14]. A large proportion of adolescent girls, up to $70 \%$ in Iran and $80 \%$ in Saudi Arabia had 25(OH)D levels $<25$ $\mathrm{nmol} / \mathrm{L}[15,16]$.

Insufficient vit $\mathrm{D}$ affects both males and females in all age groups; however, there is evidence that females have

*Address correspondence to this author at the Hamad Medical corporation Hamad general hospital, Po Box 3050, Doha, Qatar; Tel: +97444394029; Fax:+97444394031; E-mail: aymanco65@yahoo.com lower levels than males in elderly Europeans [17-19], young adolescents in Lebanon [20], and in a yearly study of the healthy aged in New Zealand [21]. This gender differences may reduce with age $[3,22]$.

Epidemiologic studies have recently linked low vit D with increased risk of cardiovascular events [23]. This association between low vit $\mathrm{D}$ level and cardiovascular disease (CVD) has never been explored in our population despite the highly prevalent low vit $\mathrm{D}$. Therefore, we explored the relationship between low Vit D and vascular risk factors in both sexes in Qatar.

\section{METHODS}

This is a retrospective, observational study that was conducted at Hamad General Hospital (HGH), Qatar. This hospital provides inpatient and outpatient tertiary care in medicine and surgery for the residents of Qatar (nationals and expatriates) making it an ideal center for population-based studies. Vit D samples were selected randomly from the central laboratory at HGH regardless of the clinic type, indication and whether patients were on vit $\mathrm{D}$ supplements. 
This was based on the previous evidence of a high prevalence of vit D among people living in the Gulf countries [813]. Inclusion criteria were males and females aged between 30 and 60 years living in Qatar. Samples from pediatric, geriatric, and oncology units were excluded. Vit D deficiency was defined as level $<30 \mathrm{ng} / \mathrm{ml}$; subdivided into mild $(20-29 \mathrm{ng} / \mathrm{ml})$ moderate $(10-19 \mathrm{ng} / \mathrm{ml})$; and severe $(<10$ $\mathrm{ng} / \mathrm{ml})$. Coronary artery disease (CAD) is defined as documented myocardial infarction (MI), angiographically proven CAD or chronic stable angina. Diagnosis of the different types of CAD and definitions of data variables were based on the American College of Cardiology (ACC) clinical data standards [24]. The presence of diabetes mellitus (DM) was determined by the previous or current medical record of a documented diagnosis of DM that had been on treatment (either oral antidiabetic agents or insulin injection). The presence of dyslipidemia was determined by the demonstration of a fasting cholesterol $>5.2 \mathrm{mmol} / \mathrm{L}$ in the patient's medical record, or any history of treatment of dyslipidemia. The presence of hypertension (HTN) was determined by any documentation in the medical record of HTN. Smoking history: patients were divided into current cigarette smokers, past smokers (defined as more than 6 months abstinence from smoking) and those who never smoked.

For measurement of vit D, we used an immunoanalyser (Liaison, Diasorin Inc). It is an automated direct competitive chemiluminescence immunoassay (CLIA) for quantitative determination of total $25-\mathrm{OH}$ vit $\mathrm{D}$ in serum or plasma. The imprecision at 56 and $19 \mathrm{ng} / \mathrm{l}$ as measured by coefficient of variation was 8.7 and $13.2 \%$, respectively.

Ethical clearance was obtained from the MRC Research Committee, HMC, for the analysis and publication of this study (IRB \#9090/09).

\section{Statistical analysis}

Data were presented as proportions or mean \pm standard deviation (SD) as appropriate. Baseline demographic characteristics, past medical history, clinical presentation, and clinical outcomes were compared between the 2 groups (males and females) using the student- $t$ test for continuous variables and Pearson chi-square $\left(\mathrm{X}^{2}\right)$ test for categorical variables. Logistic regression analysis for the predictors of CAD in low vit $\mathrm{D}$ patients was performed after adjustment for baseline variables [age, sex, DM, obesity, cholesterol and HTN]. A 2-tailed $\mathrm{P}<0.05$ was considered significant. Data analysis was carried out using the Statistical Package for Social Sciences version 18 (SPSS Inc. USA).

\section{RESULTS}

We evaluated 2000 randomly selected blood samples for vit D level between January 2008 and November 2009. Of those samples, 547 fulfilled the inclusion criteria. The overall mean age and level of vit D were $49 \pm 13$ years and 14.4 $\pm 11 \mathrm{ng} / \mathrm{mL}$, respectively. There were 498 patients $(91 \%)$ with a low vit $\mathrm{D}$ level $(<30 \mathrm{ng} / \mathrm{ml})$ with mean age of $49 \pm 12$ years whereas 49 patients $(9 \%)$ had normal vit D level (30 $80 \mathrm{ng} / \mathrm{ml})$ with mean age of $54 \pm 13$ years. In patients with low vit $\mathrm{D}$, severely low levels $(<10 \mathrm{ng} / \mathrm{ml})$ were found in 231 (46\%) patients with mean age of $46 \pm 12$ years. Fig. (1) shows a trend of steadily rising vit D levels with increasing age. The number of females and males stratified according to vit $\mathrm{D}$ levels are shown in Fig. (2). In all categories of vit D levels, the numbers of females were greater compared with males.

\section{Low Vitamin D $(<30 \mathrm{ng} / \mathrm{mL})$}

Among low vit D group, 56\% were females, 65\% were obese, $38 \%$ had HTN, $34 \%$ had dyslipidemia and $29 \%$ had DM. CAD was diagnosed by previous history of stable angina $(6 \%)$, history of MI (3.3\%) or by coronary angiography $(27 \%)$. Compared with females, males with low vit D were more likely to have DM (38 vs $22 \%, \mathrm{p}=0.001)$, dyslipidemia (41 vs $29 \%, p=0.007)$, CAD diagnosed by coronary angiography (53 vs $17 \%, \mathrm{p}=0.001$ ) and lower left ventricular ejection fraction ( 14 vs $10 \%, \mathrm{p}=0.01)$. Males were likely to have higher serum cholesterol and low-density lipoprotein $(\mathrm{P}=0.03$ and 0.003 , respectively) compared with females (Table 1). Fig. (3) shows the prevalence of CAD among males and females who had low vit D levels.

Table 2 demonstrates the predictors of CAD in the presence of low vit $\mathrm{D}(<30 \mathrm{ng} / \mathrm{ml})$. Multivariate logistic regression analysis showed that in the presence of low vit $\mathrm{D}$, age

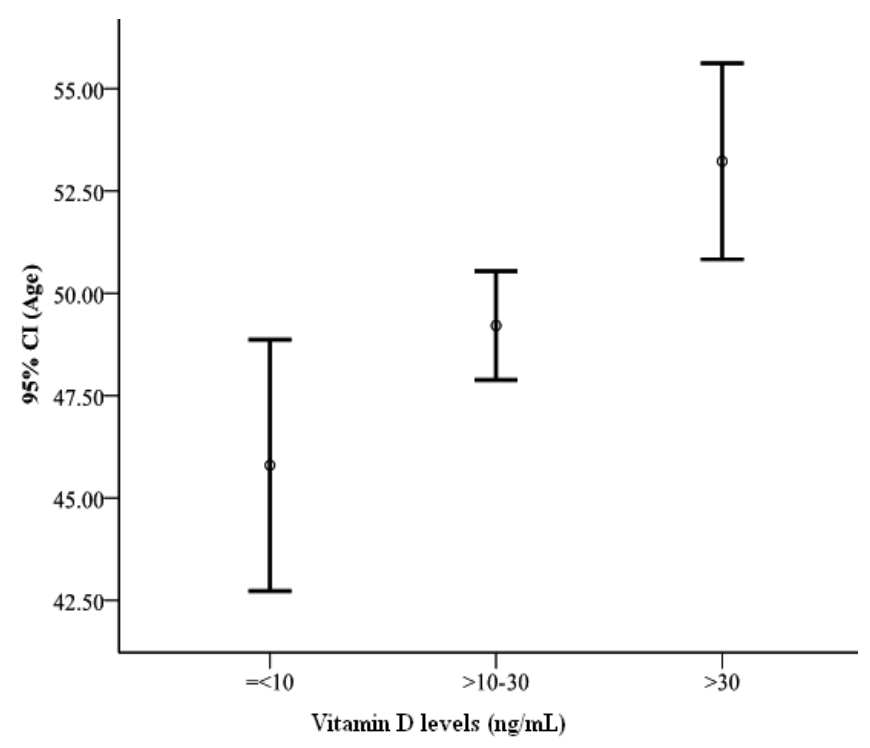

Fig. (1). Vitamin D levels according to age.

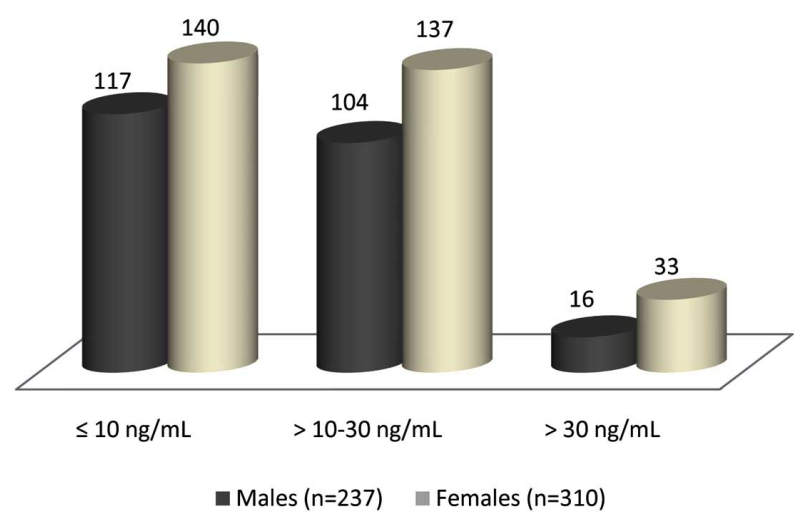

Fig. (2). Number of males and females stratified by vitamin D levels. 
Table 1. Demographic Profile and Clinical Characteristics of Patients with Low Vitamin D Levels

\begin{tabular}{|c|c|c|c|}
\hline & Males & Females & $\mathbf{P}$ \\
\hline Diabetes mellitus & $38 \%$ & $22 \%$ & 0.001 \\
\hline Hypertension & $43 \%$ & $35 \%$ & 0.052 \\
\hline Dyslipidemia & $41 \%$ & $29 \%$ & 0.007 \\
\hline Obesity & $65 \%$ & $60 \%$ & 0.31 \\
\hline Cerebrovascular disease & $1.8 \%$ & $1.5 \%$ & 0.76 \\
\hline Chronic renal failure & $1.8 \%$ & $3.3 \%$ & 0.31 \\
\hline On aspirin & $23 \%$ & $15 \%$ & 0.03 \\
\hline Hemoglobin A1c (\%) & $6.6 \pm 2$ & $6.4 \pm 1.7$ & 0.29 \\
\hline Hemoglobin $(\mathrm{g} / \mathrm{dl})$ & $12.3 \pm 12$ & $12.3 \pm 2$ & 0.64 \\
\hline Cholesterol $(\mathrm{mmol} / \mathrm{L})$ & $5.2 \pm 1.1$ & $4.9 \pm 1.2$ & 0.03 \\
\hline Triglycerides $(\mathrm{mmol} / \mathrm{L})$ & $1.8 \pm 2$ & $1.5 \pm 0.8$ & 0.07 \\
\hline Low Density Lipoprotein (mmol/L) & $3.2 \pm 1.04$ & $2.9 \pm 0.93$ & 0.003 \\
\hline High Density Lipoprotein (mmol/L) & $1.30 \pm 0.8$ & $1.31 \pm 0.4$ & 0.73 \\
\hline
\end{tabular}

$*=$ creatinine $>1.5$ upper normal range $(124 \mathrm{mmol} / \mathrm{L})$.

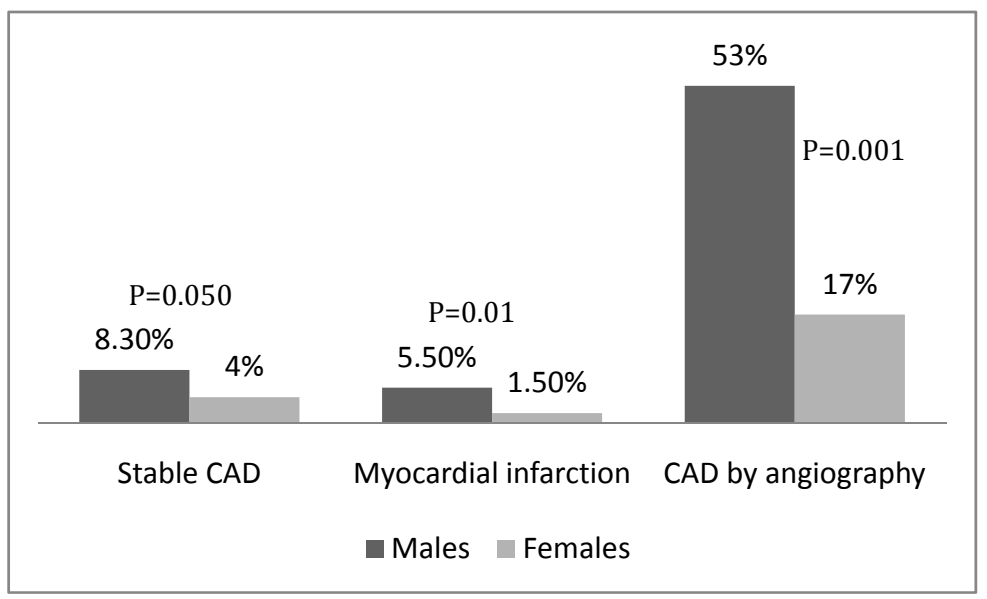

Fig. (3). Shows the prevalence of coronary artery disease among males and females who had low vitamin D levels.

and hypertension were independent predictors of CAD (OR 1.07; 95\% CI:1.02-1.11) and OR 8.0; 95\% CI:1.67-39.82), respectively.

\section{DISCUSSION}

The present study demonstrates the prevalence and impact of low vit D in males and females in a sunny country.
Our key findings were: 1) High prevalence of low vit D in Qatar. In the last few years, measuring the serum level of vit $\mathrm{D}$ is routine in most of rheumatology, general internal medicine, cardiology, geriatric, oncology and nephrology outpatient clinics. This practice was based on the high prevalence of low vit D in countries similar to Qatar in regard with traditional, cultural and environment characteristics [8-13] 2) 
Table 2. Predictors for Coronary Artery Disease in Patients with Low Vitamin D $(<30 \mathrm{ng} / \mathrm{ml})$.

\begin{tabular}{|c|c|c|}
\hline & Univariate Analysis* & Multivariate Analysis* \\
\hline \hline Age & $1.11(1.07-1.15), \mathrm{P}=0.001$ & $1.07(1.02-1.11), \mathrm{P}=0.002$ \\
\hline Sex & $0.51(0.22-0.99), \mathrm{P}=0.050$ & $0.63(0.26-1.47), \mathrm{P}=0.28$ \\
\hline Diabetes mellitus & $5.7(2.59-12.43), \mathrm{P}=0.001$ & $0.75(0.31-1.77), \mathrm{P}=0.51$ \\
\hline Obesity & $1.13(0.53-2.43), \mathrm{P}=0.75$ & $8.14(1.67-39.82), \mathrm{P}=0.01$ \\
\hline Hypertension & $26(6.26-112.50), \mathrm{P}=0.001$ & $1.08(0.44-2.66), \mathrm{P}=0.87$ \\
\hline Dyslipidemia & $4.6(2.12-10.12), \mathrm{P}=0.001$ & $\mathrm{P}=0.55$ \\
\hline
\end{tabular}

Low vit $\mathrm{D}$ is significantly associated with high prevalence of DM, dyslipidemia (high total cholesterol and LDL) and CAD in males compared with females. 3) The trend for low vit D levels fell with age. 4) Low vit D is associated with 3 times increase in the rate of MI among males. 5) HTN increases the risk of CAD 8 times in the presence of low vit D regardless of gender.

After discovery of oil, the life style in the Arab Gulf region including Qatar have become progressively more modernized based on technology, sedentary activity, and unhealthy dietary patterns [25]. These factors have led to a higher prevalence of low vit $\mathrm{D}$ despite of the presence of sun most of the year. Vit D deficiency is well recognized in Middle Eastern females as a result of cultural habit of remaining covered, while vit D level among males in this region remains under-reported. A recent study reported that $25(\mathrm{OH}) \mathrm{D}$ deficiency is common among otherwise healthy Middle Eastern male athletes [26]. Assessment of vit D deficiency among health care professionals working at $\mathrm{HGH}$ in Qatar showed the overall mean of vit D level was 11.7 $\mathrm{ng} / \mathrm{ml}$. It was lower in females $(10.3 \mathrm{ng} / \mathrm{ml})$ than in males $(13.7 \mathrm{ng} / \mathrm{ml})$ and $97 \%$ of all participants had a mean level $<30 \mathrm{ng} / \mathrm{ml}$ [27]. Furthermore, a recent study among Qatar university students showed that $53.5 \%$ of Qatari females of college age had severe vit D deficiency and $43.6 \%$ have insufficient levels of vit D [28] Low vit D predisposes to hypertension, DM, metabolic syndrome, heart failure and stroke [1,29-35]. A study of male health professionals showed a 2-fold risk of MI in subjects who were vit D deficient compared with those in the normal range [36]. The mechanism by which vit D may affect the cardiovascular system includes effects on vascular smooth muscle proliferation, inflammation and vascular calcification. Vit D deficiency activates the renin-angiotensin system leading to HTN and left ventricular hypertrophy [37-39]. However, the association between vit D status and CVD is not welldefined. Epidemiologic evidence and observational studies showed potential benefits of vit D [37]. Prospective studies demonstrated that low levels of vit $\mathrm{D}$ precede the development of CVD [40]. A follow-up study based on Health Professionals showed that males with vit D deficiency (15 $\mathrm{ng} / \mathrm{mL}$ ] had a twofold increased risk of MI, compared with those with sufficient levels of at least $30 \mathrm{ng} / \mathrm{mL}$. Furthermore, other reports demonstrated that vit D deficiency may increase CVD risk, irrespective of established risk factors for CVD [41, 42].
The high prevalence of vit D deficiency in sunny cities especially among females and younger population emphasizes the need for a recommendation to monitor $25(\mathrm{OH}) \mathrm{D}$, modify life style and nutritional habits [43-45].

Limitations of the current study included retrospective nature and lack of detailed treatment information. Data were collected randomly from the central Lab records without determination of the treatment of patients or the type of subspecialty.

\section{CONCLUSIONS}

Our study substantiates the evidence of a widespread prevalence of low vit D in the sunny regions. HTN is associated with 8 times increased the risk of CAD in the presence of low vit D regardless of gender. Therefore, screening and treatment of low vit D may be important in hypertensive patients, particularly since some evidence showed that vit D sufficiency lowers the blood pressure in hypertensive patients [46]. Low vit D is associated with 3 times increase in the rate of MI among males. However, as reports from randomized controlled trials the association between vit D and CVS are limited. There is a need for such studies in our region.

\section{CONFLICT OF INTEREST}

None declared.

\section{ACKNOWLEDGEMENT}

We thank laboratory staff of Hamad General Hospital for the technical support. The authors have no financial issues to disclose.

\section{REFERENCES}

[1] Holick M. Vitamin D deficiency. N Engl J Med 2007; 357: 266-81. [2] Peterlik M, Boonen S, Cross HS, Lamberg-Allardt C. Vitamin D and calcium insufficiency-related chronic diseases: an emerging world-wide public health problem. Int J Environ Res Public Health 2009; 6: 2585-607.

[3] Oren Y, Shapira Y, Agmon-L N, et al. Vitamin D insufficiency in a sunny environment: a demographic and seasonal analysis. Isr Med Assoc J 2010; 12: 751-6.

[4] Levis S, Gomez A, Jimenez C, et al. Vitamin D deficiency and seasonal variation in an adult South Florida population. J Clin Endocrinol Metab 2005; 90: 1557-62. 
[5] Gannage-YMH, Chemali R, Yaacoub N, Halaby G. Hypovitaminosis D in a sunny country: relation to lifestyle and bone markers. J Bone Miner Res 2000; 15: 1856-62.

[6] Van der Mei IAF, Ponsonby AL, Engelsen O, et al. The high prevalence of vitamin D insufficiency across Australian populations is only partly explained by season and latitude. Environ Health Perspect 2007; 115: 1132-9.

[7] Mishal AA. Effects of different dress styles on vitamin D levels in healthy young Jordanian women. Osteoporos Int 2001; 12: 931-5.

[8] Baroncelli G, Bereket A, El Kholy M, et al. Rickets in the Middle East: role of environment and genetic predisposition. J Clin Endocrinol Metab 2008; 93: 1743-50

[9] Mithal A, Wahl DA, Bonjour JP, et al. IOF Committee of Scientific Advisors (CSA) Nutrition Working Group. Global vitamin D status and determinants of hypovitaminosis D. Osteoporos Int 2009; 20: 1807-20.

[10] El-Hajj Fuleihan G, Deeb M. Hypovitaminosis in a sunny country. N Engl J Med 1999; 340: 1840-1

[11] Gannage-YMH, Chemali R, Yaacoub N, Halaby G. Hypovitaminosis D in a sunny country: relation to lifestyle and bone markers. J Bone Miner Res 2000; 15: 1856-62.

[12] Ghannam NN, Hammami MM, Bakheet SM, Khan BA. Bone mineral density of the spine and femur in healthy Saudi females: relation to vitamin $\mathrm{D}$ status, pregnancy, and lactation. Calcif Tissue Int 1999; 65: 23-8

[13] Saadi HF, Nagelkerke N, Sheela B, et al. Predictors and relationships of serum 25 hydroxyvitamin D concentration with bone turnover markers, bone mineral density, and vitamin $\mathrm{D}$ receptor genotype in Emirati women. Bone 2006; 39: 1136-43

[14] Lips P, Hosking D, Lippuner K, et al. The prevalence of vitamin D inadequacy amongst women with osteoporosis: an international epidemiological investigation. J Intern Med 2006; 260: 245-54

[15] Moussavi M, Heidarpour R, Aminorroaya A, et al. Prevalence of vitamin D deficiency in Isfahani High School students in 2004. Horm Res 2005; 64: 144-8

[16] Siddiqui AM, Kamfar HZ . Prevalence of vitamin D deficiency rickets in adolescent school girls in Western region, Saudi Arabia. Saudi Med J 2007; 28: 441-4

[17] Vanderwielen RPJ, Lowik MRH, Vandenberg $\mathrm{H}$ et al .Serum vitamin D concentrations among elderly people in Europe. Lancet 1995; 346: 207-10

[18] Snijder MB, van Dam RM, Visser M et al. Adiposity in relation to vitamin D status and parathyroid hormone levels: a populationbased study in older men and women. J Clin Endocrinol Metab 2005; 90: 4119-23

[19] van Dam RM, Snijder MB, Dekker JM, et al. Potentially modifiable determinants of vitamin $\mathrm{D}$ status in an older population in the Netherlands: the Hoorn Study. Am J Clin Nutr 2007; 85: 755-61

[20] El-Hajj Fuleihan G, Nabulsi M, Choucair M, et al. Hypovitaminosis D in healthy school children. Pediatrics 2001; 107: E53

[21] Bolland MJ, Grey AB, Ames RW, et al .The effects of seasonal variation of 25-hydroxyvitamin $\mathrm{D}$ and fat mass on a diagnosis of vitamin D sufficiency. Am J Clin Nutr 2007; 86: 959-64

[22] Ginde AA, Liu MC, Camargo CA Jr. Demographic differences and trends of vitamin D insufficiency in the US population, 1988-2004. Arch Intern Med 2009; 169: 626-32.

[23] Wang TJ, Pencina MJ, Booth SL, et al. Vitamin D deficiency and risk of cardiovascular disease. Circulation 2008; 117: 503-11.

[24] Cannon CP, Battler A, Brindis RG, et al. American College of Cardiology key data elements and definitions for measuring the clinical management and outcomes of patients with acute coronary syndromes. A report of the American College of Cardiology Task Force on Clinical Data Standards (Acute Coronary Syndromes Writing Committee). J Am Coll Cardiol 2001; 38: 2114-30.
[25] Fields J, Trivedi NJ, Horton E, Mechanick JI. Vitamin D in the Persian Gulf: integrative physiology and socioeconomic factors. Curr Osteoporos Rep 2011; 9: 243-50.

[26] Hamilton B, Grantham J, Racinais S, Chalabi H. Vitamin D deficiency is endemic in Middle Eastern sportsmen. Public Health Nutr 2010; 13: 1528-34.

[27] Mahdy S, Al-Emadi SA, Khanjar IA, et al. Vitamin D status in health care professionals in Qatar. Saudi Med J 2010; 31: 74-7.

[28] Sharif EA, Rizk NM. The prevalence of vitamin D deficiency among female college students at Qatar University. Saudi Med J 2011;32: 964-5.

[29] Zitterman A. Vitamin D and disease prevention with special reference to cardiovascular disease. Prog Biophys Mol Bio 2006; 92: 39-48.

[30] Scragg R, Jackson R, Holdaway IM, Lim T, Beaglehole R. Myocardial infarction is inversely associated with plasma 25hydroxyvitamin D3 levels: a community-based study. Int J Epidemiol 1990; 19: 559-63.

[31] Poole KE, Loveridge N, Barker PJ, et al. Reduced vitamin D in acute stroke. Stroke 2006; 37: 243-5.

[32] Gigolini M, Iagulli MP, Miconi V, Galiotto M, Lombardi S, Targher G. Serum 25-hydroxyvitamin D3 concentrations and prevalence of cardiovascular disease among type 2 diabetic patients. Diabetes Care 2006; 29: 722-4.

[33] Thacher TD, Clarke BL. Vitamin D insufficiency. Mayo Clin Proc 2011; 86: 50-60

[34] Martins D, Wolf M, Pan D, et al. Prevalence of cardiovascular risk factors and the serum levels of 25-hydroxyvitamin D in the United States: data from the Third National Health and Nutrition Examination Survey. Arch Intern Med 2007; 167: 1159-65.

[35] Florentin M, Elisaf MS, Mikhailidis DP, Liberopoulos EN. Vitamin D and metabolic syndrome: is there a link? Curr Pharm Des 2010; 16: $3417-34$

[36] Giovannucci E, Liu Y, Hollis BW, Rimm EB. 25-hydroxyvitamin $\mathrm{D}$ and risk of myocardial infarction in men: a prospective study. Arch Intern Med 2008; 168: 1174-80.

[37] Temmerman JC. Vitamin D and cardiovascular disease. Am Coll Nutr 2011;30: 167-70.

[38] Lee JH, O'Keefe JH, Bell D, Hensrud DD, Holick MF. Vitamin D deficiency: an important, common, and easily treatable cardiovascular risk factor? J Am Coll Cardiol 2008; 52: 1949-56.

[39] Giovannucci E. Vitamin D and cardiovascular disease. Curr Atheroscler Rep 2009; 11: 456-61.

[40] Fiscella K, Franks P: Vitamin D, race, and cardiovascular mortality: findings from a national US sample. Ann Fam Med 2010; 8: 11-8.

[41] Giovannucci E, Liu Y, Hollis BW, Rimm EB. 25-Hydroxyvitamin $\mathrm{D}$ and risk of myocardial infarction in men: a prospective study. Arch Intern Med 2008; 168: 1174-80,

[42] Wang TJ, Pencina MJ, Booth SL, et al. Vitamin D deficiency and risk of cardiovascular disease. Circulation 2008; 117: 503-11

[43] Unger MD, Cuppari L, Titan SM, et al. Vitamin D status in a sunny country: where has the sun gone? Clin Nutr 2010; 29: 784-8.

[44] Hovsepian S, Amini M, Aminorroaya A, Amini P, Iraj B. Prevalence of vitamin $\mathrm{D}$ deficiency among adult population of Isfahan City, Iran. J Health Popul Nutr 2011; 29: 149-55.

[45] Elshafie DE, Al-Khashan HI, Mishriky AM. Comparison of vitamin D deficiency in Saudi married couples. Eur J Clin Nutr 2012 14. doi: 10.1038/ejen.2012.29.

[46] Katsiki N, Athyros VG, Karagiannis A, Mikhailidis DP. Vitamin D deficiency, statin-related myopathy and other links with vascular risk. Curr Med Res Opin 2011; 27: 1691-2. 